\title{
Documento
}

\section{Origens da ANPEd: de instituída a instituinte*}

\author{
José Carmelo Braz de Carvalho
}

Departamento de Educação, Pontifícia Universidade Católica do Rio de Janeiro

As origens da ANPEd remontam a uma proposta de institucionalização de um sistema auto-regulador na política de pós-graduação em Educação, formulada pela CAPES em 1976. A partir dessa proposta da CAPES, foram realizadas reuniões de coordenadores dos Programas de PG-EDU e elaborados subsídios de estatuto por um grupo de trabalho do Grande Rio. No entanto, a proposta hiberna até 1978, quando o processo de institucionalização da ANPEd é retomado e passa a ser criticado por uma corrente instituinte, questionadora dos vínculos de uma associação nacional dos cursos de pós-graduação em Educação com a política oficial de pós-graduação.

Para delinear esta trajetória de criação institucionalizada versus instituinte, tentar-se-á recuperar quatro momentos nas origens da ANPEd: $1 .^{\circ}$ a proposta inicial da CAPES; $2{ }^{\circ}$ a reunião dos coordenadores de programas da pós-graduação em Educação, em agosto de $1976 ; 3^{\circ}$ a proposta de estatutos da ANPEd, em 1977; 4. ${ }^{\circ}$ o encontro nacional de representantes dos Programas, em março de 1978.

\footnotetext{
* Extraído do Boletim ANPEd, v. 8, n 3-4, p. 3-7, jul./dez. 1988
}

\section{A proposta inicial da CAPES, em 1976}

No contexto do Plano Nacional de Pós-Graduação em Educação (PNPG/EDU), desenvolvido pela CAPES em 1976-1977, surgem as idéias iniciais sobre a Associação Nacional dos Cursos de Pós-Graduação em Educação (observe-se bem: associação dos cursos).

Entre as diversas linhas operacionais do PNPG/ EDU, duas eram bem explícitas em relação à ANPEd:

\footnotetext{
[...] manter entre os diferentes cursos uma relação de reciprocidade que facilite uma interfertização e uma coparticipação responsável; reconhecer a importância de princípios auto-reguladores e auto-modificadores [sic] e seu poder para uma progressão integradora dos desempenhos dos cursos.
}

Nesta linha de raciocínio, reconhecia-se "a importância da integração de esforços e da comunicação e interrelação entre programas de profissionais da área", instrumentalizados através de uma associação nacional.

$\mathrm{O}$ delineamento oferecido pela assessoria do PNPG/EDU da CAPES modelava-se pela ANPEC - 
Associação Nacional de Centros de Pós-Graduação em Economia -, que oferecia as seguintes características:

1. ${ }^{\circ}$ era uma sociedade civil sem fins lucrativos;

2. ${ }^{\circ}$ eram sócios: a) programas, cursos e outros órgãos de universidades e entidades autônomas, que desenvolvessem pesquisas e formação de pessoal especializado; b) especialistas e profissionais; em caráter individual;

3. ${ }^{\circ}$ a admissão era feita por propostas de 1/5 dos membros associados, através de parecer de Comissão Especial e de decisão do Conselho Deliberativo;

4. ${ }^{\circ}$ eram seus objetivos: a) promover o intercâmbio entre as instituições associadas (cadastros de professores e pesquisadores; realização de encontros, celebração de acordos e projetos comuns; obtenção de cooperação nacional e internacional; intercâmbio de profissionais); b) incentivar a pesquisa, pela concessão de auxílios a programas e projetos institucionais e individuais; c) assegurar o debate de temas relevantes, através de encontros anuais, promoção de simpósios, seminários e reuniões; d) divulgar estudos, pela publicação de revista especializada e associação a programas editoriais de universidades e outras editoras.

A ANPEC, por seu prestígio já adquirido em 1976, inclusive através do processo integrado de seleção aos programas de $\mathrm{PG} / \mathrm{ECO}$, era assim proposta à área de educação, como modelo a ser seguido.

\section{A primeira reunião para institucionalização}

Através da coordenação do seu programa de pósgraduação da área de educação, a CAPES convocou os coordenadores de cursos então integrados ao PPG/ EDU para uma reunião na PUC-Rio, nos dias 19 e 20 de agosto de 1976.

Dizia o ofício da convocação da CAPES: "procurando consolidar a área de Educação no contexto geral das demais ciências, adotou-se, entre outras me- didas que estão sendo executadas no PNPG/EDU, a alternativa proposta para a criação de uma Associação Nacional de Cursos de Pós-Graduação da Área de Educação". Prossegue ainda o ofício: "prevê-se, nesta reunião, estabelecer as finalidades, regulamentos ou normas da referida associação, além de definir, se possível, esquemas comuns para o processo de seleção de alunos".

A essa reunião compareceram coordenadores do mestrado da UFC, UFPE, UFRJ, UFMG, UFF, UFSCar, UFBA, UnB, UFRS, PUC/SP, PUC-Rio e FGV/IESAE. Participaram também o então diretor da CAPES, professor Darcy Closs, a assessora da CAPES e coordenadora do PPG/EDU, Marilú F. Medeiros, o assessor da CAPES, Edward Kapinus e alguns professores convidados.

Com base em anotações tomadas durante os dois dias da reunião, é possível recuperar algumas dimensões de interesse. De início, foi desenvolvida uma explicação sobre a organização, objetivos e funcionamento do modelo proposto da ANPEC, com ênfase em seus princípios auto-reguladores e automodificadores e em outros aspectos já delineados no item anterior.

O então diretor da CAPES ressaltou diversos fatores considerados relevantes, como aquele relativo aos coordenadores da PG/ECO examinarem, em suas reuniões, a alocação e divisão de bolsas pelos programas; a indicação de candidatos para bolsas de estudo no exterior; bem como desenvolverem a análise de cada Programa como massa crítica da própria área de conhecimento científico. O diretor da CAPES via ainda, como vantagens desta unificação, a fixação de cotas de bolsas segundo a demanda de cada curso, o autofinanciamento das reuniões da ANPEC, via recursos institucionais. Por fim, o professor Darcy Closs instou que cada programa da PG/EDU passasse a assumir linhas definidas de pesquisa.

Em relação à especificidade da ANPEC vis-à-vis a uma congênere sua em Educação, duas ressalvas foram apresentadas por coordenadores da PG/EDU: a natureza mais acadêmica da PG/EDU, enquanto a PG/ ECO se revestia de uma natureza mais profissional externa: e o caráter pretensamente mais homogêneo 
das pesquisas econômicas, geralmente segundo modelos matemáticos, em relação à heterogeneidade das pesquisas educacionais.

Em continuidade, a reunião dos coordenadores considerou ainda as linhas de pesquisa desenvolvidas em cada programa; a consolidação de seus recursos humanos de ensino e pesquisa, através de uma política prospectiva de contratação; a vinda de professores visitantes estrangeiros; a integração do programa de bibliotecas e recursos bibliográficos; e, de forma mais ampla, o desenvolvimento de alternativas de pós-graduação lato sensu, a partir dos programas já existentes.

Como decorrência dessa primeira reunião, foi criado um grupo de trabalho constituído pelos coordenadores da PG/EDU do Grande Rio: Lyra Paixão (UFRJ), Célia Frazão Soares Linhares (UFF), Sérgio Fernandes (FGV/IESAE) e José Carmelo Carvalho (PUC-Rio), com o objetivo específico de elaborar uma minuta para os estatutos da futura Associação Nacional dos Cursos de Pós-Graduação em Educação. Esse grupo contou ainda com a colaboração de Vera Candau, que havia feito as análises iniciais do estatuto da ANPEC.

Com a focalização de reunião sobre assuntos operacionais dos projetos da CAPES e do MEC/DAU e a transferência dos encargos de redação da minuta do estatuto para um grupo de trabalho, não se observou entre os representantes institucionais da PG/EDU uma postura nítida em relação à proposta de criação da ANPEd moldada sob o modelo ANPEC. Com exceção das observações esparsas sobre as diferenças nas ênfases acadêmico-profissionalizantes entre os programas de economia e de educação e na pretensa maior heterogeneidade nas áreas e métodos de pesquisa educacional, não foram feitas críticas maiores à proposta.

\section{A fase de elaboração do anteprojeto de estatuto}

Os quatro coordenadores dos cursos de mestrado em educação do Grande Rio reuniram-se rotativamente, nas diversas instituições, por cinco vezes, entre os meses de setembro de 1976 e março de 1977. As atividades desse grupo de trabalho, para a elaboração de um anteprojeto de estatuto para a ANPEd, calcaramse largamente no estatuto da congênere ANPEC e na ficha de inscrição do CGC da mesma. Essencialmente, esse grupo de estudo procurou "reler", sob a ótica específica dos programas da PG/EDU, os temas e artigos do estatuto da ANPEC.

Em apenas quatro pontos esse anteprojeto distancio-se do estatuto da ANPEC; 1. $^{\circ}$ na sugestão de estabelecer a sede oficial da ANPEd no Distrito Federal, sob a alegação de lá estar o centro decisório da política educacional; $2{ }^{\circ}$ na eliminação da bem discriminada seção sobre as formas de atuação da ANPEC, que ocupava quase a metade das sete páginas do seu estatuto, preferindo-se não propor esta seção na minuta preparada para a ANPEd e deixar, assim, a programação da futura associação em aberto; $3^{\circ}$ na sistemática de associação prescrita para a ANPEC, bem rígida ao exigir que "qualquer nova afiliação das entidades deverá ser proposta pelo menos por $1 / 5$ dos membros associados, objeto de parecer de Comissão Especial submetido ao Conselho Deliberativo"; em contrapartida, a minuta de estatuto para a ANPEd rezava apenas que: "a admissão de sócio efetivo far-se-á por proposta de associado à Diretoria e submetida ao Conselho Deliberativo"; $4 .^{\circ}$ na fixação das categorias de sócios, que mereceu, no esboço do grupo de trabalho, uma ampliação sistemática em relação à franciscana simplicidade da associação institucional (centros, institutos, programas e entidades autônomas de pesquisa e formação de pessoal pós-graduado) e da associação individual (especialistas e profissionais de reconhecidos méritos), determinada pelo estatuto da ANPEC.

É precisamente neste ponto das categorias de sócios que o anteprojeto preparado para a ANPEd se liberaliza de uma institucionalização mais rígida, como fazia o estatuto da ANPEC, mas simultaneamente se formaliza na estratificação de níveis de status de poder $e$ prestígio. Com efeito, ao propor toda uma tipologia de sócios: do honorífico título de sócio fundador àqueles que, por força de poder burocrático, implantariam a ANPEd, aos sócios efetivos (sejam as instituições filiadas, sejam os indivíduos portadores de diplomas e vinculados a instituições 
da PG/EDU), aos sócios beneméritos, homenageados, o grupo de trabalho optou por um formalismo, sem colocar em questão a natureza institucionalizada da futura associação.

A questão do balanceamento entre o poder instituído, na representação dos programas oficiais da PG/ EDU, vis-à-vis o poder instituinte dos docentes e pesquisadores, e dos grupos não-formais não foi respondida pelo grupo de trabalho, no anteprojeto de estatuto para ANPEd. Ao propor, no artigo 9': “o Conselho Deliberativo da ANPEd será constituído de um representante de cada entidade associada", o grupo de trabalho acrescentou, em nota de rodapé, que "a admissão e a representatividade dos membros individuais (não-institucionais) no Conselho Deliberativo deverão ser objeto de apreciação pelos coordenadores da PG/ EDU em sua próxima reunião geral".

O esboço de estatuto da ANPEd foi enviado à CAPES, no primeiro trimestre de 1977 , através do coordenador de contatos com o grupo de trabalho dos mestrados do Grande Rio, Edward Kapinus. Entretanto, não ocorreu qualquer providência efetiva da CAPES para a criação da ANPEd. Por sua vez, o envio do anteprojeto de estatuto para análise pelos programas de PG/EDU que deveria ser feito, em agosto de 1977, pelo grupo de trabalho, não ocorreu.

Em 1977, o projeto de institucionalização não foi assinado pela CAPES, nem pelos programas, indicando que faltava o ímpeto necessário para criar a ANPEd, porquanto os demais projetos previstos (sistema de apoio às bibliotecas da PG/EDU, intercâmbio com professores visitantes, contratação de docentes e pesquisadores) foram implementados. Uma medida concreta para efetivação da ANPEd somente foi tomada em 1978.

Este período de hibernização ou de germinação na proposta da ANPEd parece ter sido causado por dois fatores complementares: $1 .^{\circ}$ ) internamente, na CAPES ocorreu uma solução de continuidade, pelo retorno à UFRGS da coordenadora que desencadeara a proposta da ANPEd, bem como pela saída dos quadros da CAPES do assessor Edward Kapinus; 2. $^{\circ}$ ) no âmbito dos Programas da PG/EDU, não ocorrera ain- da o devido amadurecimento e valoração da associação como instrumento de auto-regulamentação.

\section{A segunda reunião geral para institucionalização}

Graças a convênio específico entre a FGV/IESAE e a CAPES para criação da ANPEd, foi convocada uma reunião entre 14 e 16 de março de 1978, da qual participaram efetivamente 34 representantes dos diversos programas então em funcionamento, a saber: dois representantes da UnB, UNICAMP, PUC/SP, UFSM, UFRS, UFPB, UFMG; um representante da UFC, UFPE, UFSC, UFPR, UFBA, PUC/RS; da área do Rio de Janeiro dois representantes da UFF, três da UFRJ e da PUC-Rio, mais 6 representantes do FGV/ IESAE, em cuja sede estava sendo realizado o encontro nacional.

A programação da reunião incluiu seis períodos de atividades ao longo dos três dias: além de exposições gerais sobre a política de pós-graduação (pelo professor Newton Sucupira) e a política de pesquisa na pós-graduação em educação (pelo professor Tarcísio Della Senta), houve relatos temáticos e metade da programação foi destinada à análise do anteprojeto de estatuto da ANPEd, inicialmente em cinco grupos de discussão e, no último dia, em sessão plenária.

A análise dos relatos dos cinco grupos de discussão revela aceitação geral da criação da ANPEd, sem ter sido questionado, nos pequenos grupos, a natureza da institucionalização de uma associação eminentemente representativa dos Programas de Pós-Graduação em Educação. São constantes nos relatórios de grupos as questões sobre as categorias de sócios (extinguida a de sócio benemérito) e a definição da sede da ANPEd (onde residir seu presidente e não sua fixação em Brasília). Entretanto, no último dia da reunião nacional (16/3/78), durante a sessão plenária para aprovação do estatuto, aflorou o questionamento sobre o grau de institucionalização da ANPEd como órgão atuante junto à CAPES, no desenvolvimento do Plano Nacional de Pós-Graduação em Educação.

Apesar do afastamento já ocorrido no anteprojeto 
elaborado pelo grupo de trabalho, em relação ao modelo institucional da ANPEC, e apesar do reconhecimento da representatividade dos membros individuais junto ao Conselho Deliberativo da ANPEd, o questionamento levantado na sessão plenária, por um grupo de representantes, se dirigia ao âmago da questão de uma ANPEd ligada à política oficial da pós-graduação. Propugnou-se, então, que a ANPEd exercesse função instituinte, como representante da sociedade civil, ecoando mais as necessidades e interesses dos corpos docentes, discentes e de pesquisadores. Argüiu-se contra a função de uma ANPEd muito interligada ao sistema de direção do Plano Nacional de Pós-Graduação $(P N P G)$. Criticou-se ainda o critério da representatividade institucional através dos coordenadores, na suposição dos vínculos técnico-administrativos destes com o sistema de poder interno às instituições e externamente dependentes do PNPG.

Reivindicou-se, assim, uma postura mais instituin- te para a Associação Nacional de Pós-Graduação em Educação. E esta delegação de uma representatividade mais crítica através da ANPEd foi a tônica do mandato atribuído à primeira diretoria da Associação, eleita por um ano, e, em termos gerais, o espírito do estatuto então aprovado.

O grupo de sócios fundadores reuniu-se novamente em Curitiba, em maio de 1978, durante o Seminário sobre a Produção Científica nos Programas de PósGraduação em Educação: linhas de pesquisa, teses $e$ integração docente, promovido pela CAPES. Na aprovação da ata de constituição da ANPEd, foi colocado em discussão o texto do estatuto. Os participantes destacaram e propuseram modificações nos artigos ou parágrafos cuja redação tivesse escapado aos termos firmados na reunião de março. Procedeu-se, dessa forma, à retificação de alguns pontos e à ratificação dos demais, chegando-se então, à versão final do estatuto. 